\section{A PRIMER OF ART}

A Primer of Art. By John Collier. (London: Macmillan and Co., I882.)

$\mathrm{I}^{\mathrm{N}}$ this admirable little work Mr. Collier has succeeded

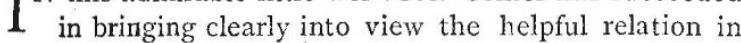
which science may stand to the Arts of Design--sculpture, drawing, and pre eminently painting. The aim of the primer is to give the outlines of such knowledge of the artistic field of vision, of the visual powers, and of the means of delineation, as may best aid the student to acquire that power of strict.imitation of natural objects which is the artist's first qualification.

The notion hitherto prevailing and perhaps somewhat superciliously beld to on the part of art-that because the primary functions of science and of art respectively are widely different, therefore no legitimate help can be rendered by one to the other-is practically discredited in every page of Mr. Collier's little work. Throughout, his object is to pioneer the student to an artistic goal; throughout, the means employed have all the security of clear scientific principle. The theory of the Primer is that by knowing with scientific accuracy how some things are, the task of exhibiting artistically how other things appear may be greatly simplified.

After devoting a few charming pages to the latest suppositions concerning the origin of sculpture and drawing -pages illustrated by specimens of prehistoric and even palæolithic art--Mr. Collier quits "debateable ground" for that on which surer scientific light can be shed for the guidance of the student in the practice of art.

And here nothing is overlooked. Boundaries, Light and Shade, Texture, Perspective, Colour, and Contrast are the headings of so many terse and luminous little chapters, through each of which comes some word to the learner from the invisible world where science works, warning him how, unless he gives heed to certain hidden actualities within and without him, he may and probably will go many times wrong before he lights on the best way of rendering the natural objects before him.

Accurate seeing is necessary to ensure accurate delineation. The facts of simple appearance are what the art student needs to lay hold of. Science, whose constant business is with facts of every order, aids him here with suggestions how to discriminate between sight and inference-between that actual aspect of an object which is due to its present relation to the sight of the observer, and that compound mental view of it which is due to the mixed memory of many previous aspects. A perusal of Mr. Collier's pages on the nature of perspective, on the undulatory theory of light, on the action of a lens, on the structure and nervous mechanism of the eye, and on the physiological rationale of the phenomena of colour show how much scientific information can be given without the use of a single technical phrase.

Having learnt to see, the art student must further learn to delineate. Here again, in discussing the painter's media, it is still with the authority of science the teacher speaks. The chapter on "Turbid Media" clears up the difficulty respecting the varying behaviour of pigments as used on different "grounds." Here, too, as elsewhere, each practical suggestion is accompanied by a scientific reason why the means advocated should be adopted, such reason being always backed by some absolutely lucid explanation of the nature of the difficulty to be surmounted, or of the effect to be aimed at.

With the subject of landscape painting comes up the question of aërial perspective; and thereupon follow some admirable pages on the constitution of the atmosphere and the refraction of light. In dealing later with certain necessary discrepancies between natural appearances and their painted imitations, Mr. Collier clears out of the way, by a simple scientific consideration, an insidious problem with which the artistic beginner is apt needlessly to Ferplex himself-namely, how correctly to represent effects of light and shade within the very limited range of luminosity afforded by his materials. The solution lies within the sphere of optics. The eye takes next to no heed of the degree of total illumination; the absolute luminosity of the picture therefore does not signify. All that is needful is to render the relative proportions of light and shade in the object or scene depicted; the effect will then be accurate, since sight adapts itself readily and unconsciously to any scale of illumination that may be visible at one time.

For the rest, this little work of Mr. Collier possesses all the attributes of a first-rate primer. As we have observed, it is terse, clear, simple, instructive, and alluring. While the student receives aid from various departments of knowledge, calculated at once to forward his progress in painting, and to enrich his ideas of the world in which he works, there is nothing attempted to which the finished artist-aware as he is of the part played by imagination and by an incommunicable sense of harmony in the production of the finest art-work - can yet take any exception. Mr. Collier frankly admits the limitations of science with regard to these points, and leaves untouched all vexed questions concerning harmony of line and colour, on the ground that, important though they are, too little is known about them to make discussion profitable.

Yet that there is no real antagonism between accurate knowledge wherever it can be had, and the loftiest artistic imagination, and further, that science may help to free that imagination by giving it mastery over its means of expression, are truths borne witness to throughout the eighty-eight pages of the primer. The scientific reader will recognise in Mr. Collier's successful endeavour to link the rival sisters (Art and Science) in friendly partnership for the better portrayal of that Nature of which hoth are students, a welcome sign of the times, and an indication of the direction in which we may look for firmer ground than has hitherto been found for fruitful artistic discussion.

L. S. BEVINGTON

\section{OUR BOOK SHELF}

A Treatise on Rivers and Canals. By L. F. VernonHarcourt, M.A. Vol. I. Text, 352 pp.; Vol. II. Plates, 2I Pl. (Oxford: Clarendon Press, I882.)

THIS work was intended (see Preface) to present " in a simple and concise form descriptions of the principal and most recent works on rivers and canals, and the principles on which they are based." It appears to have had its origin in a course of lectures delivered at the School of Military Engineering, Chatham, in 1880, but has been so carefully revised as to be free from the defects of a mere 